University of Wollongong

Research Online

Faculty of Social Sciences - Papers (Archive) Faculty of Arts, Social Sciences \& Humanities

$1-1-2016$

Infusing Physical Activities Into the Classroom: Effects on Preschool

Children's Geography Learning

Myrto F. Mavilidi

University of Wollongong, myrto@uow.edu.au

Anthony D. Okely

University of Wollongong, tokely@uow.edu.au

Paul A. Chandler

University of Wollongong, chandler@uow.edu.au

Fred Paas

University of Wollongong, Erasmus University, fredp@uow.edu.au

Follow this and additional works at: https://ro.uow.edu.au/sspapers

Part of the Education Commons, and the Social and Behavioral Sciences Commons

Research Online is the open access institutional repository for the University of Wollongong. For further information contact the UOW Library: research-pubs@uow.edu.au 


\title{
Infusing Physical Activities Into the Classroom: Effects on Preschool Children's Geography Learning
}

\begin{abstract}
In this intervention study, we investigated the effects of physical activities that were integrated into a geography task on preschool children's learning performance and enjoyment. Eight childcare centers with 87 four-to-five-year-old children were randomly assigned across an integrated physical activity condition, an unintegrated physical activity condition, and a control condition without physical activity. Children learned the names and a typical animal from each of the six continents using a floor-mounted world map with soft toy animals. Both learning conditions with physical activities showed higher performance than the learning condition without physical activities on an immediate retention test, and on a delayed retention test administered five weeks later. In addition, children in the physical activity conditions (integrated and nonintegrated) enjoyed their learning method the most. Infusing task-relevant physical activities into the classroom and the learning task is discussed as a promising way to improve children's learning, enjoyment, and health.
\end{abstract}

\section{Keywords}

children's, preschool, effects, classroom:, into, learning, activities, geography, physical, infusing

\section{Disciplines}

Education | Social and Behavioral Sciences

\section{Publication Details}

Mavilidi, M., Okely, A. D., Chandler, P. \& Paas, F. (2016). Infusing Physical Activities Into the Classroom: Effects on Preschool Children's Geography Learning. Mind, Brain, and Education, 10 (4), 256-263. 


\title{
Infusing Physical Activities into the Classroom: Effects on Preschool Children's Geography Learning
}

\begin{abstract}
In this intervention study, we investigated the effects of physical activities that were integrated into a geography task on preschool children's learning performance and enjoyment. Eighty-seven 4-5 year old children were randomly assigned across an integrated physical activity condition, an unintegrated physical activity condition, and the control condition without physical activity. Children learnt the names and a typical animal from each of the six continents using a floor-mounted world map with soft toy animals. Both learning conditions with physical activities showed higher performance than the learning condition without physical activities on an immediate retention test, and on a delayed retention test administered five weeks later. In addition, children in the physical activity conditions (integrated and non-integrated) enjoyed their learning method the most. Infusing task-relevant physical activities into the classroom and the learning task is discussed as a promising way to improve children's learning, enjoyment, and health.
\end{abstract} children

Keywords: physical activity, cognitive load theory, learning, preschool 
Infusing Physical Activities into the Classroom: Effects on Preschool

\section{Children's Geography Learning}

Research has shown that the benefits of physical activity in children are ubiquitous, including health, cognitive, and academic effects (e.g., Tomporowski, Davis, Miller, \& Naglieri, 2008). Although the academic benefits of physical activity have even been found when time for physical activity replaced part of the academic time (e.g., Sallis et al., 1997), there is a general concern in schools that time spent in physical activity is associated with a loss of academic time and school success.

Mavilidi, Okely, Chandler, Cliff, and Paas (2015) suggested that infusing physical activity into the classroom by integrating task-relevant physical activities into learning tasks might be an effective way to improve children's health and cognition, and relieve the concern about academic time loss. Indeed, the results of Mavilidi et al. (2015; see also Toumpaniari, Loyens, Mavilidi, \& Paas, 2015) showed that preschool children learned a foreign language vocabulary better, when the learning task was combined with physical activities relevant to the learning task than when it was combined with physical activities not relevant to the learning task, gestures related to the task, or with no activities at all. The present study used a similar approach, investigating whether the effects found for integrated physical activity on language learning would generalize to the domain of geography, focusing on the health and cognitive benefits of physical activity on learning.

Physical activity has positive physical and mental health effects, promoting musculoskeletal and cardiorespiratory fitness, preventing the development of some chronic diseases and conditions such as obesity, diabetes, cardiovascular diseases, and cancer, and reducing stress, anxiety and depression (e.g., Hills, King, \& Armstrong, 2007; Wamburton, Nicol, \& Bredin, 2006). In addition to the health benefits, research 
confirms the positive effects of physical activity on children's cognitive and brain functioning, and academic achievement (e.g., Fedewa \& Ahn, 2011; Khan \& Hillman, 2014; Sibley \& Etnier, 2003). Physical activity and aerobic fitness have been associated with improved cognitive control (Kamijo et al., 2011), and enhanced brain development in specific areas (such as P3 amplitude, greater grey matter volume in the hippocampus, and more effective brain activity patterns; Drollette et al., 2014; Erickson, Hillman, \& Kramer, 2015; Hillman, Castelli, \& Buck, 2005). For example, physically high fit children of 9 and 10 years of age had better free-recall and cuedrecall performance on a geography task than lower fit children (Raine et al., 2013). Kamijo, Takeda, Takai, and Haramura (2015) examined associations between aerobic fitness and inhibition of task-irrelevant information in preadolescent children (11-12 years). Based on the results of a shuttle-run test, which was administered at the beginning of the academic year, children were categorised into low and high-fitness groups. Demographic measures, as well as data on maternal education (as a measure of socioeconomic status) did not differ between groups. Results showed that higherfit children were better able to inhibit irrelevant information in an orienting task, and responded faster to target stimuli and task-relevant information than lower-fit children. To conclude, current literature suggests that fitter and more active children display a range of positive physiological and cognitive benefits.

In preschool settings physical activity has been implemented as a structured and planned activity, for example in the form of physical activity breaks, or as unstructured outdoor play (Bower, Hales, Tate, Rubin, Benjamin, \& Ward, 2008). However, with a few exceptions (see e.g., Fedewa, Ahn, Erwin, \& Davis, 2015) physical activities have not been used during learning in a way that the activities are relevant to the learning task. Fedewa et al. (2015) implemented an eight-month 
intervention to provide physical activity breaks in primary school children. Whereas children in the control group followed the regular curriculum, the experimental classrooms integrated physical activity into the academic curricula through the use of movement cards, for 20 minutes per day, five days a week. These cards consisted of aerobic-based activities (such as children doing jumping jacks with mathematical facts) lasting 5 minutes each. Results revealed that physical activity breaks improved reading and mathematics achievement.

Moreover, there is a dearth of studies focusing on the cognitive effects of movements. These studies use the theoretical framework of embodied cognition, which is about how what we do physically affects how we think. The interactions between the body and the environment offer rich sensorimotor experiences (Wilson, 2002), where conceptual representations are grounded in different modality-specific systems (i.e., perception, action emotion; Barsalou, 2008; Barsalou, Simmons, Barbey, \& Wilson, 2003). As such, cognition is grounded in action, thus linking movements with cognitive tasks can have a positive effect on learning. According to the theoretical frameworks of cognitive load theory (e.g., Paas \& Sweller, 2012; for an overview see, Sweller, Ayres, \& Kalyuga, 2011) and embodied cognition (e.g, Pouw, Van Gog, \& Paas, 2014) movements make minimal demands on working memory resources and can be used to assist in the acquisition of knowledge and skills. Furthermore, in addition to simply seeing or hearing information, taking action in response to it, creates a richer memory trace supplying alternative avenues for recalling the information later on (Chandler \& Tricot, 2015). Evidence on how encoding through subtle movements such as gestures supports memory exists widely for learning language (Macedonia \& Klimesch, 2014) and maths (Goldin-Meadow, 
Cook, \& Mitchell, 2009). Examples of empirical studies including actions and movements directly related to learning will be discussed next.

Fisher, Moeller, Crenzi, and Nuerk (2011) evaluated preschool children's performance on numerical skills. Half of the children were enrolled first in the experimental and then a tablet training condition, and the other half were enrolled in these conditions in the reversed order. Children received three training sessions per condition, lasting 10 - 15 min each. In the experimental condition, they were presented with a spatial number line using a dance mat for spatial-motor responses, whereas in the tablet training condition there was no explicit spatial information contained in the presentations or response formats. The sensorimotor spatialnumerical training was found to be more beneficial for children's arithmetic learning than non-spatial control training.

A school-based physical activity intervention program was developed to improve academic outcomes among 2nd and 3rd grade students (Mullender-Wijnsma, Hartman, de Greeff, Doolaard, Bosker, \& Visscher, 2016; Mullender-Wijnsma, Hartman, de Greeff, Bosker, Doolaard, \& Visscher, 2015). Within the program, moderate- to vigorous-intensity physical activity was integrated into mathematics and language lessons. At 2-year follow-up, children in the intervention program displayed greater improvements in learning mathematics and language than children in the control group who followed their usual classroom practices.

Classroom-based physical activity programs in elementary school-aged children have attempted to include active body movements in a meaningful way in learning by integrating physical activity with the academic content (Webster, Russ, Vazou, Goh, \& Erwin, 2015). The intervention study of Toumpaniari et al. (2015) 
examined the effects of combining physical and cognitive activities on learning foreign language vocabulary in four- and five-year-old children. Children were shown flashcards with animal names. In two 1-hour sessions per week for 4 weeks, they either had to recall the words through performing physical activities and gestures relevant to the animal words to be learnt (i.e., children had to move, walk or roll over like "dogs"), make gestures related to the animal words (i.e., children had to pose, sit or stand like "dogs"), or repeat the animal words while sitting. It was found that learning a foreign language vocabulary through physical activities and gestures resulted in the highest learning outcomes with children also enjoying this way of learning the most.

The few studies that have investigated effects of integrated physical activities on learning have focused on the domains of language or maths in primary school children. A notable exception is the study by Donnelly and Lambourne (2011), who focused on several academic content areas, including maths, geography, and science. In the geography task, children learned about the directions (north, south, east, west). Starting from a specific location where a city was called out, children were asked to run or skip in the appropriate direction. They concluded that the physically active academic lessons were enjoyable for teachers and students, and improved students' academic achievement scores. To the best of our knowledge, similar studies have not been conducted in the preschool years.

The purpose of this study was to investigate the effects of physical activities that were integrated in a geography task on preschool children's learning performance. Children were taught about the six continents of the world and one typical animal from each of the continents. The assessment of learning performance was based on children's memory of the continents and animals. Whereas previous 
studies mainly focused on direct (i.e., short-term) effects of physical activities on memory (but see Mavilidi et al., 2015), in the current study we looked at direct and delayed (i.e., long-term) effects after a 5-week delay. An integrated condition, in which children were engaged in physical activity related to the geography task (e.g., moving on the map towards the continents) was compared to a non-integrated condition, in which children were engaged in physical activity that was not related to the geography task (e.g., running around the map), and a control condition, in which children had to stand still and were taught the geography task in a conventional way (e.g., they were shown the continents on the map). Physical activity measurements were included in the analyses to examine differences in physical activity between the physical activity conditions (integrated and non-integrated) and the control group.

Based on the existing literature regarding the physiological changes and cognitive benefits associated with physical activity, it was hypothesised that the physically active children in the integrated and non-integrated condition would outperform the non-active children in the control condition on an immediate and delayed recall test. In addition, based on the theoretical framework of embodied cognition, it was hypothesised that children in the integrated condition, who performed physical activities meaningful for the geography learning task, would outperform children in the non-integrated condition, but in a non-meaningful way, on immediate and delayed recall. Finally, children were asked to evaluate the affective effects of the method that they were taught with. It was hypothesized that the teaching methods using physical activities would be rated higher than the conventional method without physical activities.

\section{Method}




\section{Participants}

Participants were 90 preschool children $\left(M_{\text {age }}=4.88 S D=.56 ; 45\right.$ boys and 45 girls) recruited in eight childcare centres. Childcare centres were randomly assigned either to the integrated physical activity condition, non-integrated physical activity or the control condition. The study was approved by the University's Human Research Ethics Committee. All parents provided written consent for their children's participation in the research. Three children were absent during the delayed test. Consequently, the total number of participants in the integrated, non-integrated, and control condition was 28,29 , and 30 , respectively. Children received stickers when they completed the activity as a reward for their effort.

\section{Materials and Procedure}

The study was conducted by the lead author at the childcare centres. It consisted of a learning and assessment phase, in which children participated on an individual basis in a separate room. The geography task included learning the six continents of the world and one characteristic animal from each continent (i.e. kangaroo in Oceania, panda bear in Asia, fox in Europe, penguin in Antarctica, giraffe in Africa, and bear in America). A world map was placed on the floor (fabric with dimensions: 550 X 520 $\mathrm{cm}$; See Figure 1). The characteristic animals (soft toys) were placed on top of each continent on the map. Children in all conditions performed the same task for 3 learning sessions lasting 10 min each. This duration was chosen to engage children's attention for a short time without mentally and physically exhausting them. The learning sessions occurred over a two-day period with a one-day break for the first week, and the same first day in the second week (e.g., MondayWednesday-Monday). Children were randomly assigned to one of the three 
conditions: in the integrated physical activity condition, children "travelled" from one continent to the other imitating the movements of the animal representing the continent (e.g., hop like a kangaroo starting from Oceania). In the non-integrated physical activity condition, children would pick up one animal at a time and then would run in a circle around the map. After their run, they would leave that animal at the same position and then pick up a different animal and run again around the map and repeat this until they finished with all the animals. Finally, in the control condition, children would stand in front of the map and look at it. The researcher would name and point at the continents and their animals while standing next to the child. The order in which the continents and the animals were shown, was the same for all the conditions (Oceania, Europe, Antarctica, Asia, Africa, and America).

The assessment included a pre-test and post-tests which evaluated children's existing and acquired knowledge, respectively. At the beginning of the learning sessions, a pre-test determined children's prior knowledge. Children were asked to name any continent they knew and any animal they knew living in a specific continent. The post-tests occurred at two different time points: a direct test at the end of the learning sessions and a delayed test 5 weeks after the learning sessions. The pre-test and the immediate test took place within a one-week period. In the pre-test, which consisted of two questions, children were asked to name the continents, and match the animals with the correct continent (each question included 6 test items). The maximum total score was 12 . In the post-tests, which consisted of four questions, children were asked to name the continents, match the animals with the right continent by placing the animals on the continent, match the continent with the right animal by naming the continent and its animal (e.g., Oceania-kangaroo), walk either from a continent of one animal to a continent of another animal (from the 
continent of the fox, to the continent of the bear, the giraffe, and the kangaroo), or walk from one continent to another (from Africa, to America, Antarctica, and Asia). For each correct answer, children received 1 point. The maximum total score was 24 (each question included 6 test items). A reliability coefficient (Cronbach's alpha) of .81 was found for the testing materials. At the end of the assessment, children evaluated how much they liked the type of instruction ("Did you like this game"), and if they would like to be taught this way in the future ("Would you like to play it again in the future?") on a 5-point Likert scale with semantic anchors (expressed as a smiley face) ranging from 1, "I didn't like it all", to 5, "I liked it a lot", and 1, "Not at all" to 5, "I would love to", respectively. This scale was adopted from the study of Toumpaniari et al. (2015). A coefficient alpha of .77 was obtained for these questions in this study.

\section{Physical Activity Measurements}

To measure children's intensity of physical activity, children were fitted with an Actigraph accelerometer (model GT3X+/BT, Pensacola, FL) worn around the waist on an elastic belt with the accelerometer positioned over the anterior aspect of the right hip upon the beginning of the learning session and removed afterwards. Actigraphs have established utility, validity, and reliability in children aged 3-5 years (Cliff, Reilly, \& Okely, 2009). Data were calculated for the scheduled 10-min time period with epoch length of 1-s intervals. Age-appropriate cut-points (Janssen et al., 2013; Pate, Almeida, McIver, Pfeiffer, \& Dowda, 2006) were used to define activity intensity. Data were reported as minutes spent in moderate, and vigorous-intensity physical activity, and the average activity counts per minute, representing the average intensity activity during lessons. 


\section{Experimental Design}

A 3 (Condition: integrated physical activity, non-integrated physical activity, control) x 2 (Time of Testing: immediate, delayed) experimental design with repeated measures on the latter factor was used. The dependent variables were children's performance at the post-test (immediate and delayed), children's interest on the type of the instruction and children's interest on the game in the future.

\section{Results}

Cook's distance indicated no outliers in the datasets and $\eta^{2}$ was used as an estimate of effect size, with $\eta^{2}=.02$ corresponding to a small effect, $\eta^{2}=.13$ corresponding to a moderate effect, and $\eta^{2}=.26$ corresponding to a large effect (Cohen, 2013).

\section{Learning outcomes}

An analysis of variance (ANOVA) with condition as independent variable and pre-test scores as dependent variable showed no significant effect of condition, $F(1$, $87)=1.19, p=.310$, indicating that children's pre-test scores did not differ across conditions (integrated condition, $M=.13, S D=.73$, non-integrated, $M=.00, S D=$ .00 , control condition, $M=.52, S D=2.19$ ).

A mixed ANOVA was performed to test the hypotheses of this study. The assumption of the homogeneity of variance was met $(p=.908$ for immediate and $p=$ .855 for delayed test). Results showed that performance was significantly affected by

time of testing, $F(1,84)=37.79, p \leq .001, \eta^{2}=.24$. Regardless of the condition, children performed better at the immediate post-test compared to the delayed posttest. In addition, there was a significant effect of condition on the test scores, $F(1,84)$ $=13.11, p \leq .001, \eta_{\mathrm{p}}^{2}=.24$. Table 1 shows the mean scores of performance at the immediate and delayed test as a function of condition. However, the interaction 
between time of testing and condition was not significant, $F(2,84)<1, p=.804$.

Post-hoc comparisons revealed that performance was significantly higher in the integrated condition $(M=16.11, S D=3.41)$ compared to the control condition $(M=$ $11.37, S D=3.61, p \leq .001)$, but not compared to the non-integrated condition $(M=$ $14.50, S D=3.76, p=.095)$. Also, the non-integrated condition $(M=14.50, S D=$ 3.76) performed better on the test scores than the control condition $(M=11.37, S D=$ $3.61, p \leq .001)$.

\section{Evaluation of Instruction}

A mixed ANOVA was conducted to examine the effects of condition and time of testing on children's evaluation of the way of learning. The evaluation of the instruction was computed as the average scores of the questions: "Did you like this game?" and "Would you like to play it again in the future?", and was measured at two moments, directly after the immediate and delayed test. Results showed that the evaluation was not significantly affected by the time of testing, $F(1,84)<1, p=.585$. However, there was a positive effect of condition on children's evaluation, $F(1,84)=$ $8.64, p \leq .001, \eta^{2}=.17$. Table 1 shows the mean scores of evaluation at the immediate and delayed test as a function of condition. The interaction between time of testing and condition was not significant, $F(2,84)=4.53, p=.228$. Post-hoc comparisons revealed that children in the integrated condition $(M=4.68, S D=.35)$ enjoyed playing this game more than children the control condition $(M=3.92, S D=$ $.98, p \leq .001)$. Also, children in the non-integrated condition $(M=4.35, S D=.61)$ enjoyed the game more than children in the control condition $(M=3.92, S D=.98, p=$ $.019)$. However, the integrated $(M=4.80, S D=.48)$ and non-integrated condition $(M$ 
$=4.76, S D=.58, p=.084$ ) did not differ in terms of how much children enjoyed playing the game.

\section{Physical Activity Outcomes}

An ANOVA was used to test children's physical activity levels across the conditions. The assumption of the homogeneity of variance was met $(p=.115)$. The units of measurement of level of physical activity were counts per minute as well as minutes of moderate- to vigorous-intensity physical activity (Pate et al., 2006). Results showed that there was a significant effect of condition on counts per minute, $F(2,202)=75.55 p \leq .001, \eta^{2}=.43$. Post-hoc tests revealed that children in the integrated condition $(M=1038.51, S D=489.01)$ were less active than children in the non-integrated condition $(M=1746.89, S D=622.22, p \leq .001)$, but children in both of these conditions were more active than children in the control condition $(M=$ 603.67, $S D=487.80$, both $p$ s $\leq .001)$.

Moreover, an ANOVA performed on the total time (min) that children spent on moderate-to vigorous-intensity physical activity (MVPA). There was a significant effect of condition on the total time spent on MVPA, $F(2,202)=111.21, p \leq .001, \eta^{2}$ $=.52$. Post-hoc tests revealed that children in the integrated condition $(M=1.71, S D=$ .71) spent less time on MVPA than children in the non-integrated condition $(M=$ 3.53, $S D=1.21, p \leq .001)$, but children in both of these conditions spent more time on MVPA than children in the control condition $(M=1.11, S D=.93$, both $p \mathrm{~s} \leq .001)$.

\section{Discussion}

This study examined the effects of integrating task-relevant physical activities into a geography learning task on immediate and delayed memory performance. Preschool children learned about the continents of the world and one characteristic 
animal for each of the continents. In the integrated condition, children performed the animal movements while going from one continent to another. In the non-integrated condition, children ran around the map holding a different animal each time. Finally, in the control condition, children were looking at the map and the animals, but no movements were involved. Results confirmed the first hypothesis that children in the physical activity conditions (integrated and non-integrated condition) would outperform children in the control condition, both on the immediate and delayed test. However, the second hypothesis that children's performance in the integrated condition would be higher than children's performance in the non-integrated condition was not confirmed.

There are several possible explanations for the fact that in contrast to Mavilidi et al. (2015; see also Toumpaniari et al., 2015), we did not find a performance benefit of relevant physical activities over non-relevant physical activities. These explanations relate to the level of activity that children in the different conditions were involved in and the relevance of the physical activities. Firstly, although the measurement of children's physical activity outcomes in this study, not surprisingly, revealed that children in the exercise groups (integrated and non-integrated condition) were more physically active than children in the control group, children in the nonintegrated condition appeared to have been more active (in terms of intensity and time spent) than children in the integrated condition. Children in the non-integrated condition had to run around the map, and therefore travelled a longer distance than children in the integrated condition, who had to run in between continents on the map. For future studies it is important that the intensity and duration of the physical activity are the same in the physically active conditions, to be able to isolate the effect of the integrated physical activity on learning performance. Secondly, with regard to the 
relevance of the physical activities, it could be argued that the activities performed in the non-integrated condition were not totally irrelevant as in the Mavilidi et al. (2015) study. In the current study, children in the non-integrated condition had to walk over a continent and pick the specific animal before starting to run around the map, enabling them to spatially locate the information to-be learned. Moreover, although not statistically significant, the means of the integrated condition were substantially higher than the means in the non-integrated condition, both on the immediate and delayed test. At this young age there is a wide spread in children's physical and cognitive development, which was reflected in the high standard deviations. A higher number of participants might be needed to reveal statistically significant differences between the integrated and non-integrated activity conditions. Finally, the soft animals were used to engage children's attention and motivation. However, children in the integrated condition may have focused more on performing the animal movements rather than spatially travelling in a specific direction across the map. Consequently, the spatial aspects of physical activity, as well as the connection of movements with the learning task, might have been obscured, resulting in the integrated condition being similar to the non-integrated condition. Indeed, in the study of Donnelly and Lambourne (2011), in which participants' attention was only focused on the directions, not on the animals, a positive effect on students' academic achievement was found. In future studies, it is important to give participants in integrated physical activity conditions the opportunity to focus their attention exclusively on the spatial aspects of the movements.

The last hypothesis of this study relating to the affective evaluation of the instructional methodology was confirmed. Children enjoyed learning through taskrelevant physical activities more than learning through physical activities that were 
not relevant to the learning task, and both ways of learning were perceived as more enjoyable than learning without physical activity. These findings are consistent with the studies of Toumpaniari et al. (2015), Vazou and Smiley-Oyen (2014) and Trost, Fees, and Dzewaltowski (2008). Alternatively, the 10-min duration for the instructional time could be sufficient for the physical activity conditions, but too long for the control condition, resulting in a reduction in children's interest and motivation for this condition, as confirmed by the evaluation of the instructional methods.

An interesting topic for future study is related to the fact that children in this study performed the activities individually. Activities occurred in a separate place, isolated from the other children who did not have the possibility to learn by seeing other children moving around the continents. Existing literature attests that observing others' movements can activate neurons related to the same actions (Rizzolatti \& Craighero, 2004; Van Gog, Paas, Marcus, Ayres, \& Sweller, 2009). Learning by performing physical activities as a group and by observing other children perform movements might have an additional benefit for learning and would be interesting to be investigated in future research.

Moreover, future research could design interventions using a teacher-led perspective to implement them in more naturalistic contexts. Last but not least, this study was conducted on a specific age group and on retention performance for a specific learning task, i.e. geography. Future research should shed light on whether these results can be generalised to other age groups, learning domains, and types of performance. With regard to type of performance, for example, it would be interesting to look at effects of integrated physical activities on the ability to apply acquired knowledge and skills on tasks that differ from the ones trained on (i.e., transfer performance). 
To conclude, the integration of physical activity into learning games seems to be an enjoyable, engaging, and promising approach to enhance learning outcomes in preschool children. This integrated approach includes activities that are very easy to be applied, are age-appropriate and in no way work at the detriment of learning. Overall, a simple and easy intervention that was implemented for a short period of time increased children's physical activity and engaged them in moderate- to vigorous-intensity physical activity. Importantly, this approach was not only perceived as interesting by children and resulted in cognitive improvements, it can also be assumed to promote a healthy and balanced well-being across the lifespan (Loeffler, Raab, \& Cañal-Bruland, 2016; Sothern, Loftin, Suskind, Udall, \& Blecker, 1999). 


\section{References}

Barsalou, L. W. (2008). Grounded cognition. Annual Review of Psychology, 59, 617645. doi:10.1146/annurev.psych.59.103006.093639

Barsalou, L. W., Simmons, W. K., Barbey, A. K., \& Wilson, C. D. (2003). Grounding conceptual knowledge in modality-specific systems. Trends in Cognitive Sciences, 7(2), 84-91. doi:10.1016/S1364-6613(02)00029-3

Bower, J. K., Hales, D. P., Tate, D. F., Rubin, D. A., Benjamin, S. E., \& Ward, D. S. (2008). The childcare environment and children's physical activity. American Journal of Preventive Medicine, 34(1), 23-29.

doi:10.1016/j.amepre.2007.09.022

Chandler, P., \& Tricot, A. (2015). Mind your body: the essential role of body movements in children's learning. Educational Psychology Review, 27(3), 365-370. doi:10.1007/s10648-015-9333-3

Cliff, D. P., Reilly, J. J., \& Okely, A. D. (2009). Methodological considerations in using accelerometers to assess habitual physical activity in children aged 0-5 years. Journal of Science and Medicine in Sport, 12(5), 557-567. doi:10.1016/j.jsams.2008.10.2008

Cohen, J. (2013). Statistical power analysis for the behavioral sciences. Routledge Academic.

Donnelly, J. E., \& Lambourne, K. (2011). Classroom-based physical activity, cognition, and academic achievement. Preventive Medicine, 52, S36-S42. doi:10.1016/j.ypmed.2011.01.021 
Drollette, E. S., Scudder, M. R., Raine, L. B., Moore, R. D., Saliba, B. J., Pontifex, M. B., Hillman, C. H. (2014). Acute exercise facilitates brain function and cognition in children who need it most: An ERP study of individual differences in inhibitory control capacity. Developmental Cognitive Neuroscience, 7, 53-64. doi:10.1016/j.den.2013.11.001

Erickson, K. I., Hillman, C. H., \& Kramer, A. F. (2015). Physical activity, brain, and cognition. Current Opinion in Behavioral Sciences, 4, 27-32. doi:10.1016/j.cobeha.2015.01.005

Fedewa, A. L., \& Ahn, S. (2011). The effects of physical activity and physical fitness on children's cognitive outcomes: A meta-analysis. Research Quarterly for Exercise and Sport, 82(3), 521-535. PMid: 21957711. doi:10.1080/02701367.2011.10599785.

Fedewa, A. L., Ahn, S., Erwin, H., \& Davis, M. C. (2015). A randomized controlled design investigating the effects of classroom-based physical activity on children's fluid intelligence and achievement. School Psychology International, 36(2), 135-153. doi:10.1177/0143034314565424

Fischer, U., Moeller, K., Bientzle, M., Cress, U., \& Nuerk, H. C. (2011). Sensorimotor spatial training of number magnitude representation. Psychonomic Bulletin \& Review, 18(1), 177-183. doi:10.3758/s13423-010-0031-3

Goldin-Meadow, S., Cook, S. W., \& Mitchell, Z. A. (2009). Gesturing gives children new ideas about math. Psychological Science, 20(3), 267-272. doi:10.1111/j.1467-9280.2009.02297.x

Hillman, C. H., Castelli, D. M., \& Buck, S. M. (2005). Aerobic fitness and neurocognitive function in healthy preadolescent children. Medicine \& 
Science in Sports \& Exercise, 37(11), 1967-1974.

doi:10.1249/01.mss.0000176680.79702.ce

Hills, A. P., King, N. A., \& Armstrong, T. J. (2007). The contribution of physical activity and sedentary behaviours to the growth and development of children and adolescents: implications for overweight and obesity. Sports Medicine, 37(6), 533-546. doi:10.2165/00007256-200737060-00006

Janssen, X., Cliff, D. P., Reilly, J. J., Hinkley, T., Jones, R. A., Batterham, M., Ekelund, U., Brage, S., \& Okely, A. D. (2013). Predictive validity and classification accuracy of ActiGraph energy expenditure equations and cutpoints in young children. PloS One, 8(11), e79124. doi:10.1371/journal.pone.0079124

Kamijo, K., Takeda, Y., Takai, Y., \& Haramura, M. (2015). Greater aerobic fitness is associated with more efficient inhibition of task-irrelevant information in preadolescent children. Biological Psychology, 110, 68-74. doi:10.1016/j.biopsycho.2015.07.007

Kamijo, K., Pontifex, M. B., O’Leary, K. C., Scudder, M. R., Wu, C. T., Castelli, D. M., \& Hillman, C. H. (2011). The effects of an afterschool physical activity program on working memory in preadolescent children. Developmental Science, 14(5), 1046-1058. doi:10.1111/j.1467-7687.2011.01054.x

Khan, N. A., \& Hillman, C. H. (2014). The relation of childhood physical activity and aerobic fitness to brain function and cognition: A review. Pediatric Exercise Science, 26(2), 138-146. http://dx.doi.org/10.1123/pes.2013-0125 
Loeffler, J., Raab, M., \& Cañal-Bruland, R. (2016). A lifespan perspective on embodied cognition. Frontiers in Psychology, 7, 845. http://dx.doi.org/10.3389/fpsyg.2016.00845

Macedonia, M., \& Klimesch, W. (2014). Long-term effects of gestures on memory for foreign language words trained in the classroom. Mind, Brain, and Education, 8(2), 74-88. doi: 10.1111/mbe.12047

Mavilidi, M. F., Okely, A. D., Chandler, P., Cliff, D. P., \& Paas, F. (2015). Effects of integrated physical exercises and gestures on preschool children's foreign language vocabulary learning. Educational Psychology Review, 27(3), 413426. doi:10.1007/s10648-015-9337-z

Mullender-Wijnsma, M. J., Hartman, E., de Greeff, J. W., Bosker, R. J., Doolaard, S., \& Visscher, C. (2015). Improving academic performance of school-age children by physical activity in the classroom: 1-year program evaluation. Journal of School Health, 85(6), 365-371. doi: 10.1111/josh.12259

Mullender-Wijnsma, M. J., Hartman, E., de Greeff, J. W., Doolaard, S., Bosker, R. J., \& Visscher, C. (2016). Physically active math and language lessons improve academic achievement: a cluster randomized controlled trial. Pediatrics, 137(3), 1-9. doi: 10.1542/peds.2015-2743

Paas, F., \& Sweller, J. (2012). An evolutionary upgrade of cognitive load theory: Using the human motor system and collaboration to support the learning of complex cognitive tasks. Educational Psychology Review, 24(1), 27-45. doi:10.1007/s10648-011-9179-2

Pate, R. R., Almeida, M. J., McIver, K. L., Pfeiffer, K. A., \& Dowda, M. (2006). Validation and calibration of an accelerometer in preschool children. Obesity, 14(11), 2000-2006. doi:10.1038/oby.2006.234 
Pouw, W. T., Van Gog, T., \& Paas, F. (2014). An embedded and embodied cognition review of instructional manipulatives. Educational Psychology Review, 26(1), 51-72. doi:10.1007/s10648-014-9255-5

Raine, L. B., Lee, H. K., Saliba, B. J., Chaddock-Heyman, L., Hillman, C. H., \& Kramer, A. F. (2013). The influence of childhood aerobic fitness on learning and memory. PloS one, 8(9), e72666. doi:10.1002/hbm.22119

Rizzolatti, G., \& Craighero, L. (2004). The mirror-neuron system. Annual Review of Neuroscience, 27, 169-192. doi:10.1146/annurev.neuro.27.070203.144230

Sallis, J. F., McKenzie, T. L., Alcaraz, J. E., Kolody, B., Faucette, N., \& Hovell, M. F. (1997). The effects of a 2-year physical education program (SPARK) on physical activity and fitness in elementary school students. Sports, Play and Active Recreation for Kids. American Journal of Public Health, 87(8), 13281334. doi:10.2105/AJPH.87.8.1328

Sibley, B. A., \& Etnier, J. L. (2003). The relationship between physical activity and cognition in children: a meta-analysis. Pediatric Exercise Science, 15(3), 243256.

Sothern, M. S., Loftin, M., Suskind, R. M., Udall, J. N., \& Blecker, U. (1999). The health benefits of physical activity in children and adolescents: implications for chronic disease prevention. European Journal of Pediatrics, 158(4), 271274. doi:10.1007/s004310051070

Sweller, J., Ayres, P., \& Kalyuga, S. (2011). Cognitive load theory (vol. 1). New York: Springer. http://dx.doi.org/10.1007/978-1-4419-8126-4 istepip

Tomporowski, P. D., Davis, C. L., Miller, P. H., \& Naglieri, J. A. (2008). Exercise and children's intelligence, cognition, and academic achievement. Educational Psychology Review, 20, 111-131. doi:10.1007/s10648-007-9057-0 
Toumpaniari, K., Loyens, S., Mavilidi, M. F., \& Paas, F. (2015). Preschool children's foreign language vocabulary learning by embodying words through physical activity and gesturing. Educational Psychology Review, 27(3), 445-456. doi:10.1007/s10648-015-9316-4

Trost, S. G., Fees, B., \& Dzewaltowski, D. (2008). Feasibility and efficacy of a "Move and Learn" physical activity curriculum in preschool children. Journal of Physical Activity \& Health, 5(1), 88-103.

Van Gog, T., Paas, F., Marcus, N., Ayres, P., \& Sweller, J. (2009). The mirror neuron system and observational learning: Implications for the effectiveness of dynamic visualizations. Educational Psychology Review, 21(1), 21-30. doi:10.1007/s10648-008-9094-3

Vazou, S., \& Smiley-Oyen, A. (2014). Moving and academic learning are not antagonists: acute effects on executive function and enjoyment. Journal of Sport \& Exercise Psychology, 36(5), 474-485. doi:10.1123/jsep.2014-0035

Warburton, D. E., Nicol, C. W., \& Bredin, S. S. (2006). Health benefits of physical activity: the evidence. Canadian Medical Association Journal, 174(6), 801809. doi:0.1139/H07-038

Webster, C. A., Russ, L., Vazou, S., Goh, T. L., \& Erwin, H. (2015). Integrating movement in academic classrooms: understanding, applying and advancing the knowledge base. Obesity Reviews, 1-11. doi:10.1111/obr.12285

Wilson, M. (2002). Six views of embodied cognition. Psychonomic Bulletin \& Review, 9(4), 625-636. doi:10.3758/BF03196322 
